\title{
Multi-Objective Intelligent Manufacturing System for Multi Machine Scheduling
}

\author{
Sunita Bansal \\ Research Scholar \\ JJTU University, \\ Rajasthan, India
}

\author{
Dr. Manuj Darbari \\ Associate Professor \\ BBD University, \\ Lucknow, India
}

\begin{abstract}
This paper proposes a framework for Intelligent Manufacturing systems in which the machine scheduling is achieved by MCDM and DRSA. The relationship between perception/knowledge base and profit maximization is being extended. Further for production function.
\end{abstract}

Keywords-Decision making; pareto; intelligent manufacturing.

\section{INTRODUCTION}

The Multiobjective function has the characteristic that there exists no fixed solution to defined problem instead it could have multiple solutions. The correlation between objectives is a very complex phenomenon and depends on the alternates available.

The multiobjective optimization consists of three phases: Model Building, optimization and decision making. To solve the problem following the true multi-objective functionality interface optimization and preference management.

In this paper we will be discussing on the issues relating to Honda Car manufacturer with Multi Assembly Line. The focus is to optimize the part versus product planning. Firstly we develop the part description which starts from the component level manufacturing.

\section{LITERATURE SURVEY}

Previous studies in the field of Decision Maker (DM) have shown good solutions in a given problems. There has been good research by Pinedo and chao (1999) in the field of flexible assembly system. Cochram et al (2001) has also analyzed how the selection of manufacturing system.

Further Seward and Nachlas (2004) also considered availability in the analysis of manufacturing systems[2]. A searching and sorting choice was been analyzed previously by Jasz kiewicz and Ferhat (1999), they later on modified it for Multiobjective[1] optimisation method. later on posterior rationality in MCDM was presented by Greco, et al (2008).

\section{IMPLEMENTATION OF MULTI -OBJeCtive FunCTIONALITY IN INTELLIGENT MANUFACTURING}

The Main focus in intelligent manufacturing system is to represent the parts in terms of its features. The feature deals with all the geometric and technological information of each feature.

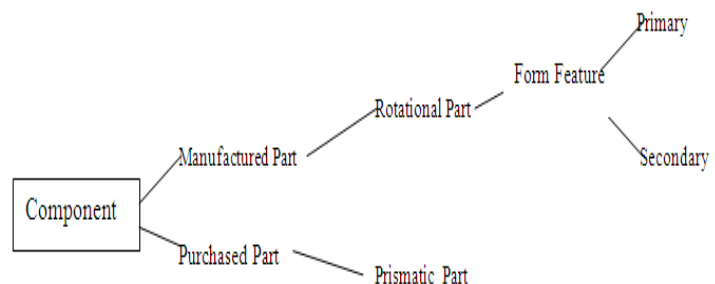

Figure 1: Part definition object Hierarchy (Adopted from 00 Approach to Features based process Planning, John H. Usher)

We handle the above part definition by applying MultiObjective optimization as:

Minimize \{f1 (Primary features), f2 (Secondary features) \}

is approach is solved by the help of Pareto optimal solution. To proceed further we define the following steps:-

1) Initialize

2) Generation of Pareto Optimal Starting Point

3) Decision making preference is sorted out.

4) Generation of New Pareto optimal Solution according to form features.

5) If several possible solutions are generated than signal the Decision Making to stop.

6) STOP

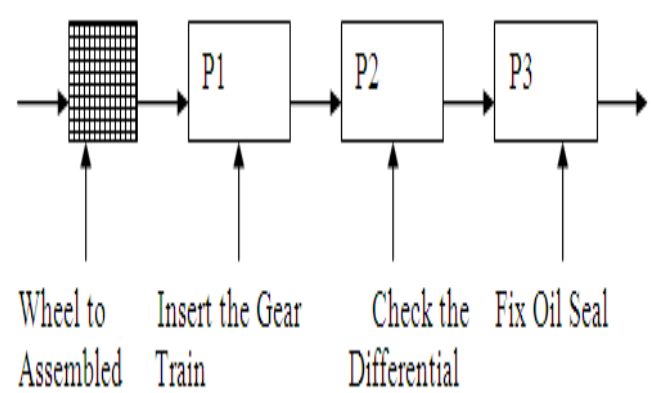

Figure 2. Assembly Line for Wheel Base 


\section{Consider layout of Toyota Fabrics}

Unit where final wheel assembly has to be done. The possible operations that can be done[3]. The possible operations that can be done to assemble the wheel deals in the following manners:

Wheel Assembly[ ] [ ] $=\{\{$ "Insert Gear, "Align Train" Gear"\},\{"Insert" Check Cross"; Alignment"\}, \{"Fill Oil Check to the specified Level"Oil Seal\}\}

Within the process hierarchy each operation can be treated as an entity which expresses the operation. These operations are solved by the use of Interactive Multiobjective optimisation using Pareto principles as stated previously. In the first stage Pareto optimal set is generated from the Machine tool settings. In the second stage, the Decision Makers (DM) provides the necessary solution to the above problem as shown in figure 3 . The Heuristic solver uses" if - then " decision rules. These rules

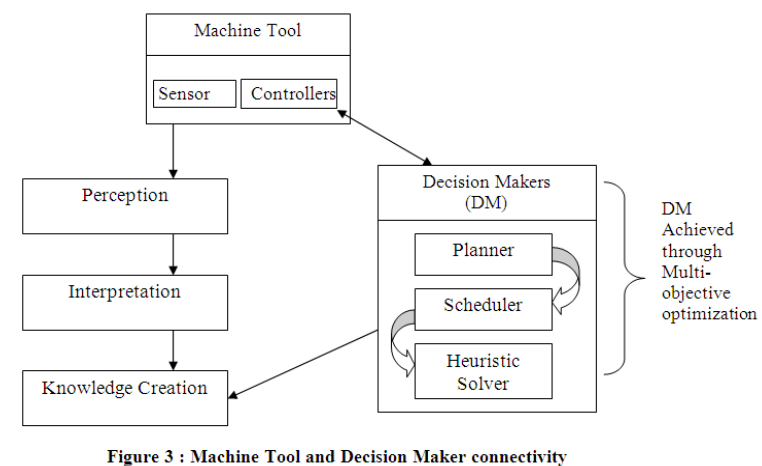
set.

Provide a solution from the currently considered optimal

It is very difficult to prioritize all of the objectives or set of goals. We use relational operator which uses the goals and priority information[4]. The ranking of whole population is based on a relationship theory.

\section{A. Implementation}

Consider an $\mathrm{n}$ - dimensional vector defined for wheel Assembly [ ] [ ]. With decision variable Maximize Output and $\mathrm{n}$ - dimensional objective vectors Perception $=\mathrm{f}$ (Maximise output $)$ and Knowledge Creation $=f$ (Maximise Output) are the two extreme requirements of Maximisation of output. Consider a preference Vector of Heuristic set rules defined as:

$\mathrm{h}=\{\mathrm{h} 1 ., \ldots \mathrm{hp}\}=\{(\mathrm{h} 11, \ldots \mathrm{hn}) \ldots$ (hp1....hpnp) $\}$

Now applying this principle of heuristic to "Perception" and "Knowledge Creation" as:

$$
\text { hpk }=\{\text { hp11, ...hpn1)..(hk11,.... hpkp) }\}
$$

The sub vector 'hp' of the associate vector represents the priorities from 1,..... p with goal $\mathrm{f}$ (Maximise Output)[5]. as:

Hence a new Pareto optimality[ ] for Convexity is obtained

!perception, knowledge Creation $\in$ Maximise Profit.

$$
\left[F_{M}(x)=\max _{i \in(1 . . . n)}\left\{\frac{f_{i}(x)-(\text { Maximise } \text { Profit })_{i}}{(\text { Perception } \wedge \text { Knoweldgecreation })_{i}}\right\}\right]
$$

(5)

From Equation 5 we can visualize the trade off between Profit Maximization and Perception, Knowledge creation as shown in figure 4.0

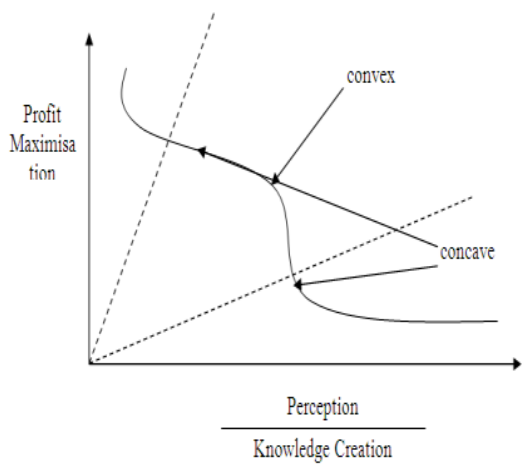

Figure 4 : Trade-off between Profit Maximization and Perception and

Knowledge Creation.

The factor of knowledge creation and perception is derived from Decision maker which has a component of Heuristic solver.

Heuristic solver user various set of rules with following variables :

$$
\begin{aligned}
& \text { Where } \mathrm{Y}=\text { Output } \\
& \mathrm{L}=\mathrm{f}\{\mathrm{L}, \mathrm{K}, \mathrm{R}, \mathrm{S}, v, \gamma\} \\
& \mathrm{K}=\text { Capour Input } \\
& \mathrm{R}=\text { Raw Materials } \\
& \mathrm{S}=\text { Land Input } \\
& \nu=\text { Return to Scale } \\
& \gamma=\text { Efficiency parameter }
\end{aligned}
$$

The heuristic model us Reference Point Substantial modeling technique which decides on the trade off in the factors described in Equation 6, it is given as:

where

$$
\mathrm{y}=\mathrm{F}(\nu, \gamma) ; \mathrm{x} \in \mathrm{S}
$$

$\mathrm{Y}=$ vector of outcomes, used for measuring the consequences of implementation of decisions.

$\mathrm{x}=$ Vector of decisions like $\mathrm{L}, \mathrm{K}, \mathrm{R}$ and $\mathrm{S}$. which can be controlled by the user.

$\gamma \& v=$ Vector of external impact which is not under users control.

$\mathrm{F}=$ Vector of functions like objective $\&$ constraints.

$\mathrm{S}=$ Set of feasible decisions.

To analyse this the vector outcomes the condition attributes are criteria and decision classes are preference ordered which means this vector of decisions like $\mathrm{x}, \gamma$ and $v$ moves to upward and downwards unions of classes[6]. 
According to DRSA if A dominate B with respect to PCI it is denoted as :

\section{ADPB for every criteria}

$$
i \in \mathrm{P}, \mathrm{fi}(\mathrm{A}) \geq \mathrm{fi} \text { (B) }
$$

The granules of knowledge used for approximate are: a set of objects dominating $\mathrm{A}$, called $\mathrm{P}$ - dominating set

$$
\mathrm{D}+\mathrm{p}(\mathrm{A})=\{\mathrm{B} \in \mathrm{U}: \mathrm{BDPA}\}
$$

A set of objects dominated by A, called P-dominating set

$$
\mathrm{D}+\mathrm{p}(\mathrm{A})=\{\mathrm{B} \in \mathrm{U}: \mathrm{ADPB}\}
$$

Now let $\mathrm{A}=\{\mathrm{x}\} ; \mathrm{B}=\{\gamma, \nu\}$ and $\mathrm{Cl}=\{\mathrm{Cl} 1 \ldots \mathrm{Clm}\}$

denotes decision classes sorting such that each $A \in U$ belongs to one and only one class $\mathrm{Ct}$.

$" \geq "$ is a comprehensive weak preference on $\mathrm{U}$ if for all $\mathrm{A}, \mathrm{B}$ $\in \mathrm{U}, \mathrm{A} \geq \mathrm{B}$ reads as " A is at least as good as B" which means

$[\mathrm{A} \in \mathrm{Cl}, \mathrm{B} \in \mathrm{Cls} \mathrm{r}>\mathrm{s}] \mathrm{yA}>\mathrm{B}$ ]

Where Clr are preferred to the object from Cls For every $\mathrm{P}$ $\subseteq \mathrm{I}$, the quality of approximation at sorting $\mathrm{Cl}$ by a set of criteria "P" is defined as The ratio of the member of object $\mathrm{P}$ consistent with the dominance principle and the number of all the objects in U[7].

The quality of approximation of sorting $\mathrm{Cl}$ with criteria as maximisation of Profit[8].

There are certain decision classes which we will derive in terms of "if .... then" ( a part of Heuristic Solver). According to DRSA a given upward or downward union of classes Clt $\geq$ or Cls $\leq$ the decision rules induced a hypothesis that objects belong to $\mathrm{P}(\mathrm{Cl} \mathrm{t} \geq)$ or $\mathrm{P}(\mathrm{Cls} \geq)[9]$.

There are three types of decision rules :

1) Certain $D \geq-$ decision rules, providing lower profile of the objects like $\gamma$ and $v$.

2) Certain $\mathrm{D}<$-decision rules providing the maximum values of the considered criteria like $\mathrm{L}, \mathrm{K}, \mathrm{R}$ and $\mathrm{S}$.

3) Approximate $\mathrm{D} \geq \leq$ - decision rules, providing simultaneously lower and upper profiles of objects like $\mathrm{x}$ versus $\gamma$ and $v$.

A set of decision rules is complete if it represents all the objects[10].

Applying these rules to "Theory of Production". We have the plot between the two dominated objects as : $\mathrm{x}$ and $\gamma$ and $v$.

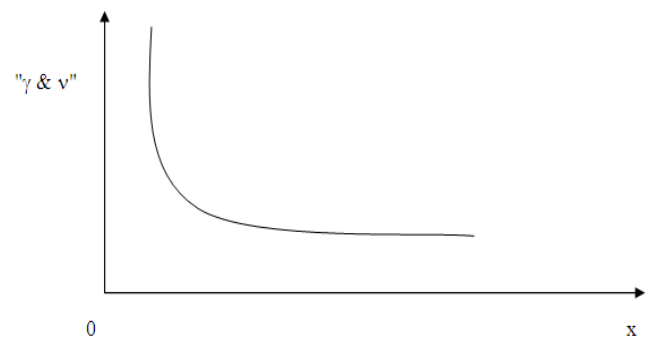

Figure 5 : Under Normal condition the relationship between two objects " $x "$ and " $\gamma \& v "$.

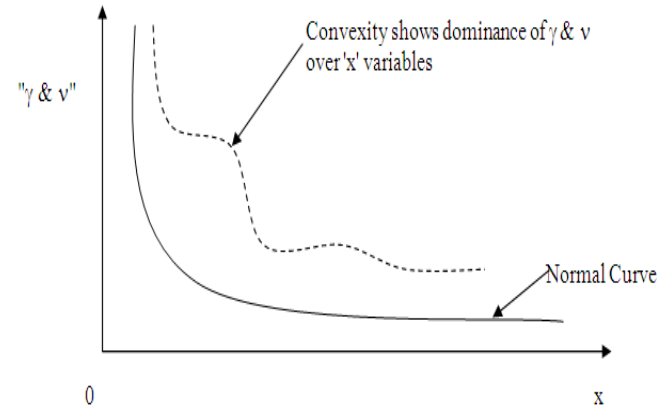

Figure : 6 Optimised graphical Plot showing the Hypothesis

The convexity shows dominance of optimizing "return to scale" and "Efficiency parameter".

\section{CONCLUSION}

The paper gives a brief overview of the Pareto optimal set and Decision maker (DM) which shows a good solution to the production problem in which we have DRSA to find out the dominance of the variables in the factor of production.

By solving using the dummy variables we are able to derive the optimised graph of the solution vector for production function.

\section{REFERENCES}

[1] Aguirre, H. E., Tanaka, K., Sugimura, T. and Oshita, S. (2001). Halftone image generation with improved multiobjective genetic algorithm. In Proceedings of the First International Conference on Evolutionary MultiCriterion Optimization (EMO-2001), pp. 510-515

[2] Antonisse, J. (1989). A new interpretion of scheme notation that overturns the binary encoding constraint. In Proceedings of the Third International Conference on Genetic Algorithms, pp. 86-91.

[3] Arora, J.S. (1989). Introduction to Optimum design, New York: McGraw-Hill

[4] Bagchi, T. (1999). Multiobjective Scheduling by Genetic Algorithms, Boston: Kluwer Academic Publishers

[5] Deb, K.(1999a). Evolutionary algorithms for multi-criteria optimization in engineering design. In K. Miettinen, P. Neittaanmaki, M. M. Makela and J. Periaux (Eds), Evolutionary Algorithms in Engineering and Computer Science, pp. 135-161. Chichester, UK:Wiley

[6] Deb, K. and Goel, T. (2001b). A hybrid multi-objective evolutionary approach to engineering shape design. In proceedings of the Third International Conference on Genetic Algorithms, pp. 42-50

[7] Deb, K. . Multi-objective evolutionary algorithms: Introducing bias among Pareto-Optimal solutions. In A. Ghosh and S. Tsutsui (Eds), Theory and Applications of Evolutionary Computation: Recent Trends. London: Springer-Verlag

[8] Fonseca, C. M. and Fleming, P.J. (1998a). Multiobjective optimization and multiple constraint handling with evolutionary algorithms - Part I: A unified formulation. IEEE Transactions on Systems, Man and Cybernetics, Part A: Systems and Humans 28(1), 26-37

[9] Goldberg, D.E. (1989). Genetic Algorithms for Search, Optimization and Machine Learning. Reading, MA: Addison-Wesley

[10] Horn, J., Nafploitis, N and Goldberg, D. (1994). A niched Pareto genetic algorithm for multi-objective optimization. In Proceedings of the first IEEE Conference on Evolutionary Computation, pp. 82-87 
AUTHORS PROFILE

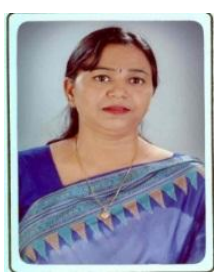

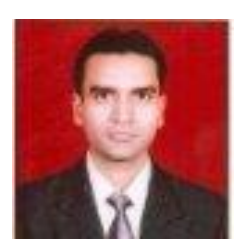

Manuj Darbari is currently working as an Associate Professor in Information Technology at Babu Banarasi Das National Institute of Technology \& Management, Lucknow. His teaching areas are ERP, MIS, Soft Computing. He has published ten papers in referred international and national journals. He was selected for Marquis who's who in science and engineering 20032007. His teaching areas are Information Science, ERP, Software Engineering, and Workflow Management. 